\title{
PENGARUH PENERAPAN SENAM HOOK UPS TERHADAP TINGKAT PERCAYA DIRI ANAK
}

\author{
R.Nur Abdurakhman*, Eva Latifatul Fajriyah**
}

\begin{abstract}
ABSTRAK
Salah satu aspek yang perlu diperhatikan pada siswa sekolah adalah percaya diri (self confidence), percaya diri merupakan salah satu modal dalam kehidupan yang harus ditumbuhkan pada setiap siswa agar mereka dapat menjadi manusia yang bisa mengontrol berbagai aspek yang ada pada dirinya.masalah fisik, obesitas dan kurangnya berat badan, keterlambatan dalam menerima pelajaran dikelas, yang mengakibatkan seorang anak kurang percaya diri. salah satu metodenya yaitu dengan memberikan gerakan senam hook ups. Adapun tujuan penelitian ini adalah untuk mengetahui pengaruh penerapan senam hook ups terhadap peningkatan percaya diri anak kelas dua. Metode penelitian yang digunakan adalah eksperimen semu atau quasy eksperimen tanpa kelompok pembanding (one group pretest and post test), dengan jumlah sampel sebanyak 35 siswa/i kelas dua MIN Guwa Kidul. Pengumpulan data selama satu bulan untuk pre test dilakukan dengan responden mengisi kuisioner sebelum intervensi, post test dilakukan pengumpulan data pada minggu ke empat . Uji statistik dengan Uji Paired $t$ - test dengan nilai t- post test 85.636 dan $p$ Value 0.000.Hasil uji statistik didapatkan bahwa ada perbedaan tingkat percaya diri sebelum dan sesudah dilakukan senam Hook Ups dengan nilai mean 0,32 dan menunjukkan ada peningkatan tingkat percaya diri setelah dilakukan senam Hook Ups ( $p$ value 0,000).
\end{abstract}

Kata Kunci : senam Hook Ups, tingkat percaya diri.

\begin{abstract}
One aspect to note is the school student confidence (self-confidence), self-confidence is one of the capital in a life that must be grown on each student so that they can be a man who can control every aspect of the physical dirinya.masalah, obesity and lack of weight gain, delays in receiving lessons in class, which resulted in a child's lack of confidence. one method is to provide the hook ups gymnastics movement. The purpose of this study was to determine the effect of the application of gymnastics hook ups to the increased confidence graders.

The method used was experimental or quasi-experimental Quasy without comparison groups (one group pretest and post-test), with a sample size of 35 students / class i MIN Guwa two Kidul. The collection of data for a month to pre-test conducted with respondents fill out questionnaires before the intervention, post-test data collection at week four. Test statistics with the Paired t- test, post test 85.636 and p Value 0.000.

Statistical test results showed that there are differences in confidence levels before and after exercise Hook Ups with a mean of 0.32 and showed no increase in confidence levels after exercise Hook Ups ( $p$ value 0.000).

Keywords : gymnastics Hook Ups, confidence level.
\end{abstract}

\footnotetext{
* Staf Pengajar Program Studi D III Keperawatan STIKes Cirebon

** Alumni PSIK STIKes Cirebon Lulus Tahun 2014
} 


\section{LATAR BELAKANG}

Perkembangan anak meliputi segala perubahan yang terjadi pada anak, baik secara fisik, kognitif, emosi, dan psikososial. Kemampuan anak untuk meraih prestasi dan bersosialisasi dengan lingkungannya terkait dengan perkembangan psikososialnya, yang salah satunya dibutuhkan rasa percaya diri. Percaya diri merupakan hal yang sangat penting dimiliki oleh setiap orang, tidak terkecuali anak anak. Sebagian besar anak sangat mudah merasa rendah diri, karena merasa tidak mampu dan tidak penting. ${ }^{1}$

Individu yang tidak percaya diri biasanya disebabkan karena individu tersebut tidak mendidik diri sendiri dan hanya menunggu orang melakukan sesuatu kepada dirinya. Dengan kepercayaan diri yang cukup, seseorang individu akan dapat mengaktualisasikan potensi yang dimilikinya dengan yakin dan mantap. ${ }^{2}$

Salah satu aspek yang perlu diperhatikan pada siswa sekolah adalah percaya diri (self confidence), percaya diri merupakan salah satu modal dalam kehidupan yang harus ditumbuhkan pada setiap siswa agar mereka dapat menjadi manusia yang bisa mengontrol berbagai aspek yang ada pada dirinya, dengan adanya kemampuan dan percaya diri siswa akan lebih jernih dalam mengatur tujuan dan sasaran pribadi yang jelas, bukan hanya itu siswa juga lebih mampu dalam mengarahkan perilaku menuju keberhasilan terutama keberhasilan dalam meningkatkan prestasi belajar.

Banyak orang sukses di Indonesia dan negara Timur lainnya, menggunakan pemahaman untuk menyelesaikan masalah yang dihadapi. Di Negara Barat justru lebih banyak menggunakan rasionya. Berarti kesuksesan akan lebih mudah diperoleh apabila mampu menggunakan intuisi (otak kanan) dan rasio (otak kiri). menurut riset yang pernah dilaporkan, hanya $3 \%$ penduduk dunia yang menggunakan otaknya secara seimbang. ${ }^{3}$ cara melatih agar otak kiri dan otak kanan anak berkembang sama baiknya dan menjadi seimbang, seimbang antara kecerdasan emosional (EQ) dan Intelektual (IQ) sehingga munculah kecedasan spritual (SQ) yang baik juga. ${ }^{1}$

Otak mausia adalah aset yang sangat berharga dalam diri manusia tidak ada satupun benda buatannya yang mampu menandingi kemampuan otak sekalipun pada computer paling canggih. Sebab pada dasarnya semuanya bersumber dari otak. Namun sayangnya, ia hanya memanfaatka paling banyak $10 \%$ dari kemampuan otaknya. ${ }^{4}$

Otak adalah bagian tubuh yang berfungsi sebagai pusat pengendalian organ - organ tubuh, otak selau berhubungan dengan intelegensia atau kecerdasan seseorang, otak juga merupakan system pengendalian pikiran dan system tubuh yang menjalakan beberapa fungsi secara bersamaan. ${ }^{4}$

Senam otak adalah serangkaian latihan berbasis gerakan tubuh sederhana. Gerakan itu dibuat untuk merangsang otak kiri dan kanan. Melalui senam otak, bagian - bagian otak yang sebelumnya tertutup akan terbuka dan menandakan bahwa kegiatan belajar berlangsung dengan menggunakan seluruh otak. Senam otak dapat dilakukan oleh segala usia mulai dan bayi hinnga usia lanjut. ${ }^{4}$

Senam hook ups merupakan salah satu bagian dari senam otak,gerakan senam hook ups pun terkait relaks, karena gerakan dari senam hook ups lebih kearah positif, yang membuat seseorang lebih relaks, tenang, adanya keseimbangan jasmani dan koordinasi, serta untuk lebih meningkatkan rasa percaya diri.

Senam hook ups mengaktifkan potensi belahan otak (hemisfer) kanan dan kiri, sehingga pada akhirnya terjadi kerja sama antar keduanya. Kedua hemisfer ini disambung dengan corpus callosum, yakni simpul saraf kompleks dimana terjadi transmisi informasi antar belahan otak. Bila sirkuit-sirkuit informasi dari kedua belahan otak cepat menyilang, maka 
anak akan merasakan lebih segar dari sebelumnya dan lebih konsentrasi sehingga lebih mudah menyerap ilmu dan merasa lebih percaya diri. ${ }^{1}$

Setelah melakukan studi pendahuluan pada tanggal 6 Desember 2013 di MIN Guwa Kidul, peneliti melihat anak kelas dua MI, yang berjumlah 35 siswa, anak - anak tersebut kurang mempunyai rasa kepercayaan diri, mereka masih malu - malu untuk berinteraksi dengan teman sebayanya serta gurunya, bahkan untuk memperkenalkan diri di depan kelas, mereka masih ada keraguan, kurangnya kemandirian anak seperti, berangkat sekolah masih di antar orang tunya, masih di temani saat sekolah, hal ini juga merupakan salah satu penyebab anak merasa kurang percaya diri. Anak tersebut terkesan manja, oleh karena itu ketika tampil di depan kelas timbulnya rasa kurang percaya diri. Tumbuh kembang siswa kelas 2 MI pada umur $6-8$ tahun seharusnyamereka bisa mengekspresikan reaksi terhadap orang lain, mampu mengontrol emosi, mempunyai sahabat, sudah mau pisah dengan orang tuanya tanpa rasa takut, dan bisa memahami salah atau benar. Alasan peneliti memilih siswa kelas 2 MI, karena siswa kelas 2 MIN cenderung mengalami percaya diri yang rendah akibat belum terbiasa berpisah dengan orangtuanya,dan penurunan tumbuh kembang dibandingkan dengan siswa kelas lainnya.

Masalah-masalah yang sering muncul pada anak usia sekolah SD/ MI, masalah fisik, obesitas dan kurangnya berat badan, yang merupakan suatu gangguan fisik yang mengakibatkan seorang anak kurang percaya diri, keterlambatan akademik dimana seorang anak memiliki intelegensi yang cukup tinggi tapi tidak bisa memanfaatkan secara optimal, sangat lambat belajar, penguasaan materi yang rendah, tidak adanya motivasi untuk anak lebih giat belajar, dan lebih percaya diri , kesulitan dalam membaca (disgraphia),dan kesulitan dalam menghitung (dyscalculia), berkelahi, berbohong, dan agresi atau perilaku menyerang secara fisik (non verbal) maupun kata - kata, agresi ini salah satu bentuk kekecewaan karena tidak terpenuhi kebutuhan, agresi inijuga bisa dalam bentuk sikap seperti, memukul, mencubit, dan menendang. Masalah - masalah tersebut bisa memacu kurangnya percaya diri pada anak usia sekolah.

Masalah kepercayaan diri siswa bisa menjadi hambatan untuk kehidupannya, siswa menjadi kurang mandiri dalam melakukan aktivitas, kurang kreatif, penuh keraguan dalam melakukan tindakan, mengalami tingkat kegelisahan yang berat, dan frustasi, sehingga anak anak tersebut perlu adanya suatu tindak lanjut untuk mengatasi problema tersebut, salah satu metodenya yaitu dengan memberikan gerakan senam hook ups. Senam hook ups merupakan bagian gerakan dari senam otak yang bertujuan agar anak - anak merasa nyaman dilingkungan sekitarnya, lebih relaks, dan lebih berani dalam hal - hal positif, sehingga bisa meningkatkan percaya diri.

\section{METODE PENELITIAN}

Rancangan penelitian yang digunakan peneliti pada penelitian ini adalah eksperimen semu atau quasi experiment design, penelitian ini mengungkapkan hubungan sebab akibat dengan cara melibatkan satu kelompok subyek. Kelompok subyek diobservasi sebelum dilakukan intervensi, kemudian diobservasi lagi setelah dilakukan intervensi. ${ }^{5}$

Rancangan penelitian ini tergambar dalam tabel di bawah ini:

\begin{tabular}{llll} 
& \multicolumn{3}{c}{ Rancangan Penelitian } \\
\hline Subyek & Pre-test & Intervensi & Post-test \\
\hline A & 01 & I & 02
\end{tabular}


Keterangan :

A : Kelompok responden (Anak Usia Sekolah)

I : Intervensi senam hooks ups

01 : Hasil pengukuran percaya diri sebelum intervensi

02 : Hasil pengukuran percaya diri setelah intervensi

Populasi penelitian adalah anak sekolah. MIN Guwa Kidul anak kelas dua MI, yang berjumlah 35 siswa. Pengambilan sampel pada penelitian ini adalah dengan teknik total sampling yaitu didasarkan pada suatu pertimbangan tertentu yang dibuat oleh peneliti sendiri, berdasarkan ciri atau sifat-sifat populasi yang sudah diketahui sebelumnya. Sampel ini juga berdasarkan responden yang memenuhi kriteria inklusi :

1) Anak kelas dua yang mengikuti senam hook ups, di MIN Guwa Kidul

2) Anak kelas dua yang bersedia menjadi responden, di MIN Guwa Kidul

Analisa data dengan univariat yang dilakukan pada setiap variabel hasil penelitian dan analisa bivariat dilakukan terhadap dua variabel yang diduga berpengaruh. Analisis data akan dilakukan dengan menggunakan perangkat lunak pengolah data statistik.

Analisa univariat dimaksudkan untuk mendeskripsikan masing-masing variabel, yaitu variabel bebas yaitu senam hook ups serta variabel terikatnya yaitu peningkatan percaya diri. Analisis univariat pada penelitian ini menggunakan tehnik tendensi sentral. Sedangkan analisis bivariat menggunakan uji statistik paired t-test dengan batas kemaknaan $5 \%$.

\section{HASIL PENELITIAN}

\section{Tingkat Percaya Diri Sebelum dilakukan senam hook ups anak kelas dua MIN}

Tabel 1 Distribusi frekuensi tingkat Percaya Diri anak kelas dua MIN Guwa Kidul Kecamatan Kaliwedi kabupaten Cirebon sebelum dilakukan senam hook ups, tahun 2014

\begin{tabular}{ccc}
\hline Klasifikasi & Frekuensi & $\%$ \\
\hline Tinggi & 17 & 51.4 \\
Rendah & 18 & 48.6 \\
\hline Jumlah & 35 & 100
\end{tabular}

Tabel diatas menunjukan bahwa sebagian besar responden (Anak kelas dua MIN Guwa Kidul) memiliki tingkat Percaya Diri yang tinggi (57\%) sebelum dilakukan senam hook ups dan yang lainnya pada tahap tingkat percaya diri yang rendah (43\%).

Tabel 2. Rata - Rata Tingkat Percaya Diri Sebelum Perlakuan

\begin{tabular}{lcccccc}
\hline & $\begin{array}{l}\text { Jumlah } \\
\text { Subyek }\end{array}$ & $\begin{array}{l}\text { Rata-rata } \\
\text { Percaya Diri }\end{array}$ & Median & Modus & Min-Max & $\begin{array}{l}\text { Std. } \\
\text { Deviasi }\end{array}$ \\
\hline $\begin{array}{l}\text { Sebelum } \\
\text { Perlakuan }\end{array}$ & 35 & 25,57 & 26 & 20 & $17-38$ & 5,842 \\
\hline
\end{tabular}

Tabel diatas menunjukkan keadaan tingkat percaya diri sebelum diberikan intervensi senam hook ups. Dengan jumlah subjek 35, yang memiliki Rata - rata tingkat percaya diri 
rendah $(25,57)$ dengan nilai median(26), nilai modus(20), nilai minimum-maksimum (17$38)$.

\section{Tingkat percaya diri sesudah dilakukan senam hook ups anak kelas dua MIN}

Tabel 3. Distribusi frekuensi tingkat Percaya Diri anak

\begin{tabular}{ccc}
\hline Klasifikasi & Frekuensi & $\%$ \\
\hline Tinggi & 35 & 100 \\
\hline Jumlah & 35 & 100 \\
\hline
\end{tabular}

Pada tabel diatas menunjukkan bahwa adanya peningkatan setelah dilakukan senam hook ups yaitu sebelumnya anak kelas dua memiliki tingkat percaya diri rendah menjadi percaya diri tinggi (100\%).

Tabel 4. Rata - Rata Tingkat Percaya Diri Sesudah perlakuan

\begin{tabular}{lcllccc}
\hline & $\begin{array}{l}\text { Jumlah } \\
\text { Subyek }\end{array}$ & $\begin{array}{l}\text { Rata-rata } \\
\text { Percaya Diri }\end{array}$ & Median & Modus & Min-Max & $\begin{array}{c}\text { Std. } \\
\text { Deviasi }\end{array}$ \\
\hline $\begin{array}{l}\text { Sesudah } \\
\text { Perlakuan }\end{array}$ & 35 & 32.29 & 32.00 & 31 & $29-39$ & 2.230 \\
\hline
\end{tabular}

Tabel diatas menunjukkan keadaan tingkat percaya diri sesudah diberikan intervensi senam hook ups., dengan jumlah sebjek 35 , Rata - rata tingkat percaya diri tinggi $(32,29)$, dengan nilai median $(32,00)$, nilai modus (31), nilai minimum-maksimum (29-39).

Tabel 5. Distribusi Pengaruh Senam Hook Ups terhadap Tingkat Percaya Diri Anak Kelas Dua MIN Guwa Kidul Kecamatan Kaliwedi Kabupaten Cirebon Tahun 2014

\begin{tabular}{ccc}
\hline Intervensi & Jumlah subjek & Rata-rata \\
\hline Sebelum & 35 & 25.57 \\
\hline Sesudah & 35 & 32.29 \\
\hline
\end{tabular}

Tabel diatas menunjukan perbedaan rata-rata tingkat percaya diri anak kelas dua MIN Guwa Kidul sebelum dilakukan senam hook ups percaya diri rendah (25.57 ) dan sesudah dilakukan senam hook ups percaya diri tinggi (32.29).

Pengaruh penerapan senam hook ups terhadap tingkatan percaya diri anak kelas dua di MIN

Tabel 6. Uji Paired T-Test

\begin{tabular}{ccccccc}
\hline & $\mathrm{N}$ & Mean & Std.deviasi & $\begin{array}{c}\text { Std.eror } \\
\text { Mean }\end{array}$ & $\mathrm{T}$ & $p$-value \\
\hline Pre & 35 & 25.57 & 5.842 & .988 & 25.894 & .0001 \\
\hline Post & 35 & 32.29 & 2.230 & .377 & 85.636 & .0001 \\
\hline
\end{tabular}


Tabel diatas menunjukan rata-rata sebelum dilakukan senam hook ups percaya diri rendah (25.57) standar deviation (5.842), standar eror mean (0.988), nilai $P$-value (0.001), sesudah dilkukan senam hook ups rata-rata tingkat percaya dri menjadii (32.39), standar deviation sesudah (2.230), standar eror mean (0.377), nilai P-value (0.001).

\section{PEMBAHASAN}

\section{Tingkat percaya diri sebelum intervensi}

Hasil rata- rata tingkat percaya diri sebelum dilakukan intervensi senam hook ups pada anak- anak kelas dua MIN Guwa Kidul termasuk tingkat percaya diri rendah 25.57. Hal ini di sebabkan karena faktor - faktor yang mempengaruhi rasa percaya diri, salah satunya lingkungan sekitar mereka yang kurang mendukung untuk anak tersebut bisa mengembangkan potensi yang ada pada diri anak-anak, serta kurangnya motivasi orang tua yang membuat perilaku anak tersebut kurang mandiri sehingga membuat anak kurang percaya diri.

Sebelum dilakukan intervensi senam hook ups, tingkat percaya diri pada anak kelas dua MIN Guwa Kidul tergolong rendah. Hal ini terlihat dari perilaku anak - anak tersebut, mereka masih malu - malu untuk berinteraksi dengan teman sebayanya serta gurunya, bahkan untuk memperkenalkan diri di depan kelas, mereka masih ada keraguan, kurangnya kemandirian anak seperti, berangkat sekolah masih di antar orang tuanya, masih di temani saat sekolah, hal ini juga merupakan salah satu penyebab anak merasa kurang percaya diri. Anak tersebut terkesan manja, oleh karena itu ketika tampil di depan kelas timbulnya rasa kurang percaya diri. Dapat disimpulkan tingkat percaya diri rendah pada anak kelas dua MIN Guwa Kidul disebabkan karena lingkungan keluarga, yang membuat anak tersebut manja dan merasa malu berinteraksi dengan teman sebayanya.

\section{Tingkat Percaya Diri Sesudah Intervensi}

Berdasarkan hasil penelitian yang dilakukan pada anak- anak Kelas Dua di MIN Guwa Kidul kecamatan Kaliwedi kabupaten Cirebon, rata-rata tingkat percaya diri sesudah intervensi selama satu bulan dengan melakukan gerakan senam hook ups tingkat percaya diri tinggi 32,29, median 32,00, modus 31, serta standar deviasi 2,230, yang menunjukan ada peningkatan percaya diri setelah dilakukan intervensi.

Pada penelitian sebelumnya dari observasi tingkat kepercayaan diri sesudah dilakukan senam hook ups dengan 61,98 grm dengan standart deviasi 14,607 grm yang berarti rata-rata anak mempunyai kepercayaan diri sedang. Terlihat nilai mean perbedaan antara hasil observasi pre dan post adalah 10,65 grm dengan standart deviasi 2,20 grm. Hasil uji statistik didapatkan nilai $\rho=0,000$ maka dapat disimpulkan ada pengaruh senam hook ups yang signifikan terhadap kepercayaan diri.

Pada Penelitian ini setelah dilakukan senam hook ups selama 1 bulan intervensi selama 15 menit anak - anak kelas dua MIN Guwa Kidul, mengalami perkembangan tingkat percaya diri yang signifikan di bandingkan dengan tingkat percaya diri sebelum intervensi. Hal ini bisa terjadi karena selama satu bulan responden mengikuti intervensi senam hook ups yang manfaatnya dapat membantu meningkatkan tingkat kepercayaan diri, sehingga tingkat percaya diri anak meningkat. Tingkat percaya diri tinggi pada anak-anak kelas dua MIN Guwa Kidul dapat dilihat dari perubahan perilaku anak yang lebih mandiri, aktif bertanya, dan bisa lebih tenang dalam mengerjakan tugas di sekolah. 


\section{Pengaruh Penerapan Senam Hook Ups Terhadap Tingkat Percaya Diri Siswa Kelas Dua MIN Guwa Kidul}

Berdasarkan penelitian yang telah dilakuakan pada anak kelas dua MIN Guwa Kidul kepercayaan diri sesudah dilakukan hook ups di MIN Guwa Kidul terjadi peningkatan, yang diperoleh data bahwa ada peningkatan rata-rata percaya diri pada anak kelas dua MIN Guwa Kidul, metode pengambilan sampel secara total sampling menujukan bahwa rata-rata percaya diri sebelum intervensi 25.57 menjadi 32.29 setelah intervensi, rata-rata peningkatan percaya diri 6.72. dengan nilai mean 32.29 kepercayaan diri ini masuk kategori percaya diri tinggi, berdasarkan alat ukur yang digunakan oleh peneliti terdapat 10 pertanyaan. Dari hasil di atas sesudah dilakukan senam hook ups sebagian besar responden mengalami peningkatan tingkat percaya diri yang dilakukan selama 15 menit setiap 3 kali dalam seminggu selama 1 bulan, peningkatan tingkat percaya diri tersebut di dukung oleh responden yang kooperatif saat diberikan intervensi. Responden tertarik saat melakukan senam hook ups.

Mekanisme kerja senam hook ups adalah dengan adanya gerakan kait relaks memindahkan energi listrik dari pusat pertahanan hidup (survival centers) di bagian otak bagian belakang ke otak bagian tengah (system limbis) dan neo cortex, tempat pusat-pusat untuk pemikiran yang masuk akal. Dengan demikian, mengaktifkan integrasi kedua belahan otak, meningkatkan koordinasi motorik halus, dan meningkatkan pemikiran logis.

Penelitian Setiyo tahun 2009 menunjukkan gerakan brain gym memberikan kontribusi terhadap kecemasan anak sekolah. Temuan ini semakin mendukung pernyataan yang disampaikan oleh Dennison, Paul E., and G.E Dennison bahwa individu dari berbagai usia menggunakan program brain gym untuk memperoleh perbaikan yang cepat. Hubungan aktivitas dengan kondisi otak dengan cara metode brain gym dan exercise adalah untuk meningkatkan penyaluran oksigen, penyaluran darah, dan penyaluran asam amino ke bagian cortex sehingga otak menjadi segar dan berfungsi efektif dan otak belahan kiri dan belahan kanan akan sehat jika mengikuti aktivitas pikiran.

Setelah dilakukan Penelitian selama 1 bulan di dapatkan rata-rata kenaikan tingkat percaya diri sebesar 6.72, dengan demikian bisa ditarik kesimpulan bahwa setelah melakukan senam hook ups minimal satu minggu tiga kali pada anak-anak kelas dua MIN Guwa Kidul dapat meningkatkan tingkat percaya diri pada anak-anak kelas dua MIN Guwa Kidul.

\section{SIMPULAN}

1. Tingkat Percaya Diri Sebelum dilakukan Senam Hook Ups

Percaya diri pada anak kelas dua MIN Guwa Kidul sebelum dilakukan senam hook ups memiliki tingkat percaya diri rendah.

2. Tingkat Percaya Diri Sesudah dilakukan Senam Hook Ups

Percaya diri pada anak kelas dua MIN Guwa Kidul setelah dilakukan senam hook ups mengalami percaya diri tinggi

3. Pengaruh Penerapan Senam Hook Ups terhadap Tingkat Percaya Diri

Terdapat pengaruh senam hook ups yang dilakukan oleh peneliti selama satu bulan dengan intensitas waktu seminggu tiga kali selama lima belas menit, terhadap tingkat percaya diri pada anak kelas dua MIN Guwa Kidul. Tingkat percaya diri sebelum dilakukan senam hook ups rendah, setelah dilakukan senam hook ups selama satu bulan menjadi tinggi .

\section{SARAN}

1. Bagi Kesehatan

Sebaiknya dijadikan bahan masukan yang bermanfaat untuk meningkatkan rasa percaya diri pada anak dengan gerakan senam hook ups. 
2. Bagi Peneliti Lain

Sebaiknya dilakukan penelitian mengenai faktor-faktor yang mempengaruhi percaya diri pada anak.

3. Bagi Instansi Pendidikan MIN Guwa Kidul

Diperlukan upaya yang sistematis dalam pemberian senam hook ups sehingga lebih meningkatkan percaya diri pada siswa.

4. Bagi Orang Tua dan Masyarakat

Adanya sosialisasi secara mendalam pada Orang tua siswa dan Masyarakat tentang penerapan senam hook ups pada anak dan manfaat senam hook ups untuk meningkatkan percaya diri pada anak.

5. Bagi Anak MIN Guwa Kidul

Diharapkan dapat melakukan senam hook ups secara rutin setelah mengetahui penerapan dan manfaat senam hook ups.

\section{DAFTAR PUSTAKA}

1. Suharsono Toni. Dr. dr. Achidat. Pengaruh Penerapan Senam Hook Ups terhadap Peningkatan Kepercayaan Diri pada Anak Usia 3-4 tahun di PAUD Mentari dan PAUD Al-Sha Desa Sidorahayu- Wagir Kabupaten Malang.[diakses tanggal 3 November 2013]. Diunduh dari:old.fk.ub.ac.id/artikel/id/.../Kiki\%20Giardika.pdf.

2. Hamdan . Hubungan Antara Kepercayaan Diri Dengan Motivasi Berprestasi Pada Siswa SMUN 1 Setu Bekasi. [diakses tanggal 17 Desember 2013]. Diunduh dari:www.gunadarma.ac.id/library/.../Artikel_10504066.p.

3. Rohayati Iceu. Program Bimbingan Teman Sebaya Untuk Meningkatkan Percaya Diri Siswa.[diakses tanggal 23 November 2013]. Diunduh dari:jurnal.upi.edu/file/36ICEU_ROHAYATI.pdf.

4. DR. Kartini. Kartono. Psikologi Anak. Psikologi Perkembangan. Bandung:Mandar Maju;2007

5. Notoatmojo Sukijo.Metodologi Penelitian Kesehatan.Jakarta:Rineka Cipta;2007

6. Hurclock. Elizabeth B. Perkembangan Anak jilid 1 Edisi ke Enam. Erlangga Jakarta: Erlangga;2007 